\title{
Incentives for Using Internet and Its Addiction among Adolescents in Rural Area in Tanta City, Egypt
}

\author{
Amaal Mohamed Ahmed El-Zeftawy ${ }^{1}$, Samira El- Sayed El- Mezayen ${ }^{2}$ \\ ${ }^{1}$ Assistant Professor, ${ }^{2}$ Lecturer of Community Health Nursing, Faculty of Nursing, Tanta University, Egypt
}

\begin{abstract}
Background: One of the problems elicited with the development of new technology, especially among adolescents is Internet addiction. Because of a high prevalence of the interpersonal problems associated with Internet addiction so it had been considered as an important social problem in different countries.

Aim of the study: - to identify incentives for using the Internet and its addiction among adolescents in the rural area.

Subjects and Method: -Study design: - In this study an analytic cross-sectional study design was used.

Study settings: - The study was conducted in twelve preparatory and three secondary schools in the rural area of Tanta city.

Study subjects: - Stratified random sampling and simple random sampling were used to choose the schools and students. Seven hundred and thirty - six (736) students had been selected randomly and were willing to take part in this study.

Tools of data collection: - A third -part questionnaire was used by the researchers.

First part: - Demographic data of the participants.

Second part: - Participants were required to provide some details on their internet use.

Third part: - Internet Addiction Test (IAT) Scale which was developed by Al-Osaymi (2010).

Results:-The result of this study showed that of the 736 students who were participated in this study, 370 (50.3\%) were female, 366 (49.7\%) were male and their age ranged from 12-18years. About $37.8 \%$ of the students were internet addicted, $36.7 \%$ were excessive Internet use and $25.5 \%$ were normal Internet use.

Conclusion and recommendation: - It can be concluded that in rural areas the Internet addiction is one of a growing problem among adolescents. Therefore, it is necessary to operate new strategies for prevention and control of Internet addiction, which is vital for saving use of the Internet and promoting healthy

Keywords: Adolescents, Internet addiction, Al-Osaymi Internet addiction scale .Rural area
\end{abstract}

\section{Introduction}

Adolescents are an essential resource of any nation and the most dynamic critical short period in the human life cycle. The expert committee of World Health Organization(WHO)stated adolescence as a period between 10-19yrs.Today, about one-fifth of the world's populations are 10-19 years of age, representing 1.2 billion adolescents, and 1.5 billion young people aged between 10-24 years in the world. The most $85 \%$ of them are living in developing countries ${ }^{(1-3)}$. Adolescence is the stage of transition. Though the Internet is channel for rapid communication and very important source of information, many concerns are needed for its abuse among the adolescents ${ }^{(1,3,4)}$.

In the current century, a lot of and different of new inventions have come in our daily lives. The computer and, by expansion, the Internet particularly among adolescents are the most common inventions in the present-day worldwide and have had the highest influence on our daily lives ${ }^{(5)}$. The prevalence of Internet addiction has increased rapidly due to the Internet has animated into businesses, internet café, schools, and homes, Internet addiction is described as badly controlled Internet use and can lead to impulse-control disorders $(6,7)$.

Internet user individuals have increased from 360 million in December 2000 to 2.4 billion in June 2012 worldwide; this illiterate's that worldwide Internet penetration is $34.3 \%$ of the population. In Asia, it has increased from 114 million Internet users in December 2000 to 1.07 billion in June 2012; this show's that internet breakthrough in Asia is $27.5 \%$ of its total population ${ }^{(8)}$. Internet addiction widely varies through international estimates. Many studies illustrate that the prevalence of adolescent's Internet addiction was reported between $7.9 \%$ and $22.8 \%{ }^{(9)}$. As of December 31, 2012, there were 145 million Internet users aged 6 to 19 years ${ }^{(6)}$.

Adolescent's incentives for using Internet were observed in interact conveniently with each other, gain social support online, improve their level of psychological well-being, meet new individuals and setup new 
relationships through sites of social networking, easily obtain necessary acquaintance and sources about a especial subject, and get information and news on news taking place at any place through the world. Internet addiction has become an important part of students' life. The use of the Internet in academic contexts was originally intended for learning and research ${ }^{(10-12)}$.

However, excessive or inappropriate Internet use can lead to Internet addiction, which has been defined as a case in which people are unable to restraint and control their desire to use the Internet, lose their sense of time importance when using the Internet, suffer from excessive nervousness, stress, and aggressiveness when forbade of Internet use, and experience a gradual drop in function, socialization, and family life ${ }^{(13)}$ Newly, because of the high prevalence of psychiatric symptoms, depression, interpersonal problems, and aggressive behavior, associated with Internet addiction especially among adolescents therefore, it has been considered as an important social problem in different countries ${ }^{(14,15)}$ Low parental involvement, low educational level of parents, parental unemployment, being so young when using the Internet for the first time, overusing of social and game network sites have been considered as risk factors for Internet addiction among adolescents. Other risk factors as the parental conflict and inadequate oversight on unessential Internet use have been reported by another studies as the main causes of Internet addiction ${ }^{(9,14,15)}$.

Adults are less vulnerable to Internet addiction than adolescents ${ }^{(3)}$. Many reasons are responsible for making the adolescents as a probable risk group vulnerable to Internet addiction like as ;settle a lot of time on the Internet for recreation, chatting, forming sites and socialization; undertake a main function within society in the adoption of recent values, combine the group/section that uses this technology with the greatest facility, and hence represent the most important target group for content producers; and show much concern in recent technology, using the Internet to a major extent than other age groups, even though they have not yet reached full psychosomatic ripeness ${ }^{(16,17)}$.

The accessibility of electronic information is the main aspect of differs rural communities from other urban. The rural adolescents with their rural inquisitiveness may explore and test the possibilities of the Internet when they are risky to such new technology for the first time. ${ }^{(4)}$.Based on the reality that the Internet is today an attendant part of our daily lives, it is important to explore Internet use between the adolescents and youth to effectively protect them from the harms and threats to the internet environment, and to instruct children and adolescents on the perceptible use of the internet ${ }^{(18)}$. In conformity with these observations and acquaintance, our aim was to find incentives for using the Internet and its addiction among adolescents in the rural area.

\section{Aim of the study.}

The aim of the present study was to identify incentives for using internet and its addiction among adolescents in rural area.

\section{Research questions}

1. What are the most common places and methods of Internet using among adolescents?

2. What are the incentives and causes of adolescents using of Internet?

3. Are the rural adolescents suffering from Internet addiction?

\section{Study design:-}

\section{Subjects and method}

Study design was used in this study was an analytic cross-sectional.

Study settings:-

This study was conducted in 15 governmental schools (12 preparatory schools out of 51 schools and 3secondary schools out of 10 schools) these schools were randomly selected using stratified and simple random sample technique to represent $25 \%$ of all governmental preparatory and secondary schools in rural areas in both east and west educational zones in Tanta city.

The following table shows the number of schools in each educational zone

\begin{tabular}{|c|c|c|c|c|}
\hline $\begin{array}{c}\text { Educational } \\
\text { zone }\end{array}$ & $\begin{array}{c}\text { Preparatory } \\
\text { schools }\end{array}$ & $\begin{array}{c}\text { Selected 25\% of } \\
\text { schools }\end{array}$ & $\begin{array}{c}\text { Secondary } \\
\text { schools }\end{array}$ & $\begin{array}{c}\text { Selected 25\% } \\
\text { of schools }\end{array}$ \\
\hline East zone & 30 & 7 & 6 & 2 \\
\hline West zone & 21 & 5 & 4 & 1 \\
\hline Total & 51 & 12 & 10 & 3 \\
\hline
\end{tabular}

\section{Study subjects:-}

Stratified random sampling and simple random sampling were used to choose the schools and students. Seven hundred and thirty- six (736) students had been selected randomly and were willing to participate in this study. 
One classroom from each preparatory school and two classrooms from each secondary school were selected randomly. The total number of students in each classroom was ranged from 35-45 student who had used the Internet at least once a week for the past 6 months at their home, school, book store, coffee network, or any other related place.

\section{Tools of data collection}

A third - part questionnaire was used by the researchers to identify incentives of internet use and its addiction among adolescents in rural areas.

First part: - Demographic data of the participants. This included age, sex, academic year, father and mother educational level, father and mother's work, income, family size, crowding index, sanitation and student's order. Second part: - In the second part. Participants were required to provide some details on their internet use such as favorite forms of Internet, the number of hours of use Internet per week, number of years of Internet use, average of hours of using of Internet after school each day, average of hours of using Internet during holiday search day, the most common places for using Internet, the method to connect with Internet, the motives for using the Internet, the preferred settings of Internet and factors lead to Internet addiction .

Third part: - Internet Addiction Test (IAT) Scale by Al-Osaymi SAM (2010) (19. It is a reliable and valid test of Internet addiction, advanced by Al-Osaimi SAM(2010). It consists of 79 items that gauges who were and not Internet addiction. The students were called for rating items on a three -point Likert scale (from $1=$ little degree, $2=$ moderate degree and $3=$ large degree). The lower score is 79 , and the ultimate score is 237 , the highest score, the greatest the problems internet use causes. The 79 items is divided into eight domains. The first domain (ten items) measures salience. The second domain (ten items) measures mood modification. The third domain (ten items) measures tolerance. The fourth domain (ten items) measures withdrawal symptoms. The fifth domain (ten items) measures conflict. The sixth domain (eight items) measures relapse. The seventh domain (ten items) measures dependence. The eighth domain (eleven items) measures abuse.

The total score for eight domains was categorized as:-

- $\quad$ Normal Internet use: - less than $50 \%$ (less than 118 of the total score)

- $\quad$ Excessive Internet use: - from50\% to less than 70\% (from 118to less than 165.5 of the total score).

- Internet addicted: - more than $70 \%$ (more than 165.5 of the total score).

\section{Methods}

1. The researchers gained an official permission to conduct the study from Dean of Faculty of Nursing Tanta University which was directed to the Directorate of Education, El-Gharbia Governorate and from him to the educational district in Tanta city. Also, the approval and cooperation of schools' directors and headmasters in rural areas was gained to carry out the study.

2. The structured interview questionnaire sheet part one and two was prepared by researchers according to recent literature review. These developed parts of the tool were handed out to experts of 5 academic professors in Community Health Nursing department to test its content and face validity. Accordingly, rectification and modulations were done. But part three was adopted from Al-Osaymi SAM (2010 $)^{(19)}$ only the researchers use three Likert scales instead of five Likert scales used in the original article.

3. Test the tool for relevance, clarity, and reliability was done by a pilot study that was carried out on (about $10 \%$ of the studied sample) $(n=80$ adolescents (students)). Those adolescents were shut out from the total number of the study sample. Cronbach's Alpha detected reliability of tool which is 0.72 .

4. The current study: -The gathering of the data continuous during a period of three months startedfrom the second week of the first term of the academic year 2016-2017.

5. Informed consent was gained from the selected adolescents to involve in the study and acquainted students about the aim of the study, the privacy and confidentiality of any input presented to the researchers.

6. Field work: - Questionnaires were administered in selected schools from the first of October to the end of November 2016. A questionnaire was administered during school day, in the existence of one (or two) researcher(s) and in most times an educator, as required by local or school rules and to make control on the class. For ensuring confidentiality and to minimize the probable of a reporting bias the self-completion mode was used among study subjects. Students were informed of the nature and aim of the study and content of the questionnaire by the researchers and were given instructions on the completion of the questionnaire. The researchers encouraged the participants to ask questions and details of how this could be done were explained; general questions would be answered to the whole class before to fill the questionnaire, while individual questions would be answered privately after the start to assure singularity and avoid cut out the whole class. Moreover, before starting the study adolescents were informed about their right to draw from the study at the beginning. Only adolescents had intact with the Internet only participate in the study. The time of completion was typically 45 minutes. 
7. Modified social score for family social leveling ${ }^{(20)}$.

The total score of modified social score for family social leveling was 46 points. The total modified social score for family social leveling of the studied adolescents was classified into three categories as follows:-

* High Social Level: $\geq 85 \%$ (38 - 46) of the total score.

* High Middle Social Level: $-75 \%-<85 \%$ (34.5 - < 38) of the total score.

* Low Middle Social Level: $50 \%-<75 \%(23-<34.5)$ of the total score.

*Low Social Level: $<50 \%(<23)$ of the total score.

8. Statistical analysis

SPSS (version 20) was used for coding, entering, and analyzing the data. Descriptive statistics (frequency numbers Percentages) identified demographic characteristics and students' responses to the questionnaire. Examine the correlations between domains of Internet addiction spearman correlation was used. statistical significant was set at $\mathrm{P}$ value $<0.01$.

\section{Results}

Table (1): represents the distribution of the studied school children according to their socio- demographic characteristics. It shows that their age was ranged from 12-18years with mean $14.59 \pm 1.48$ years. Half of them (50.3\%) were female and anther half $(49.7 \%)$ were male. More than two- thirds of students $(65.3 \%)$ of the school children from preparatory school while, more than one- third of them $(34.7 \%)$ from secondary school. Regarding order of the students in their family, it shows that more than one- third (39.3\%) of them were the first child for their families and only $(2.9 \%$ and $0.7 \%)$ of them were the fifth or more.

Table (1): Distribution of the studied students according to their socio- demographic characteristics

\begin{tabular}{|l|c|c|}
\hline \multirow{2}{*}{$\begin{array}{c}\text { Socio-demographic } \\
\text { Characteristics }\end{array}$} & \multicolumn{2}{c|}{ The studied students(n=736) } \\
\cline { 2 - 3 } & \multicolumn{2}{|c|}{$\%$} \\
\hline Age & 135 & 18.3 \\
\hline $12-$ & 377 & 51.2 \\
\hline $14-$ & 199 & 27.1 \\
\hline $16-$ & 25 & 3.4 \\
\hline 18 & \multicolumn{2}{|c|}{$14.59 \pm 1.48$} \\
\hline Range & \multicolumn{2}{|c|}{} \\
\hline Mean \pm SD & 366 & 49.7 \\
\hline Sex & 370 & 50.3 \\
\hline Male & \multicolumn{2}{|c|}{} \\
\hline Female & 481 & 65.3 \\
\hline Students' school & 255 & 34.7 \\
\hline Preparatory school & \multicolumn{2}{|c|}{} \\
\hline Secondary school & 289 & 39.3 \\
\hline Student's birth order & 226 & 30.7 \\
\hline First & 124 & 16.8 \\
\hline Second & 71 & 9.6 \\
\hline Third & 21 & 2.9 \\
\hline Fourth & 5 & 0.7 \\
\hline Fifth & & \\
\hline More than fifth & & \\
\hline
\end{tabular}

Figure (1): represents the distribution of the studied students' fathers and mothers' level of education. It shows that about two fifths $(42.8 \%$ and $40.1 \%)$ of the study students' mothers and fathers' level of education were secondary school and only $(19.1 \%$ and $8 \%)$ of them were illiterate.

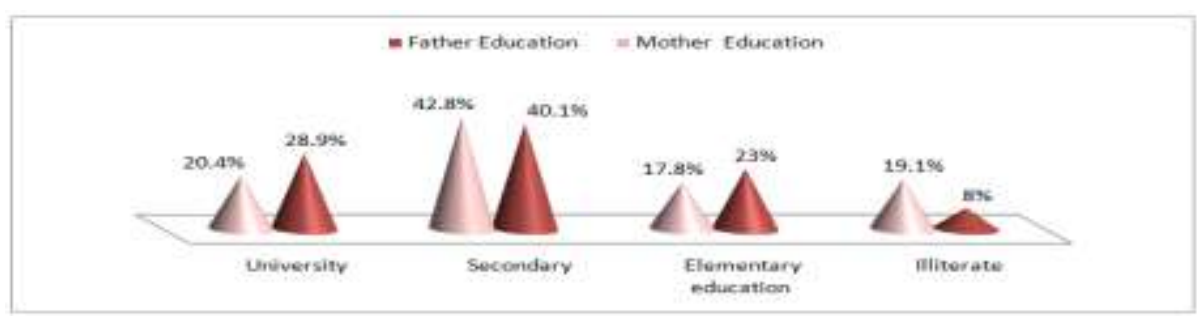

Figure (1): Distribution of the studiedstudents' fathers and mothers' level of education. 
Figure (2): represents the distribution of the studied students' fathers and mothers; occupation. It shows that the majority (91.6\%) of the study students' fathers was worked and only $8.4 \%$ of them don't work while threequarters $(75.4 \%)$ of their mothers was worked and about slightly less than one- quarter $(24.6 \%)$ of them don't work.

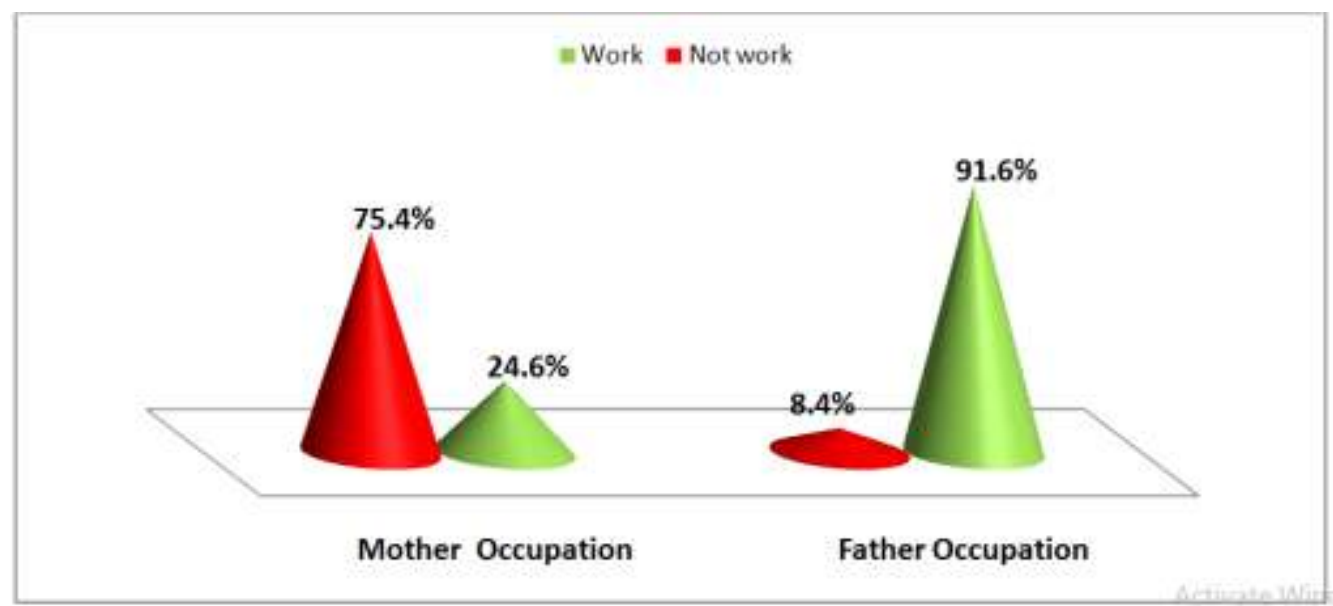

Figure (2): Distribution of the studied students' fathers and mothers' occupation.

Figure (3): represents the studied students according to their family score of social level. It shows that slightly more than one- third $(36.5 \%$ and $34 \%)$ of the study students were high and low middle social levels while $8.2 \%$ of them were low social levels.

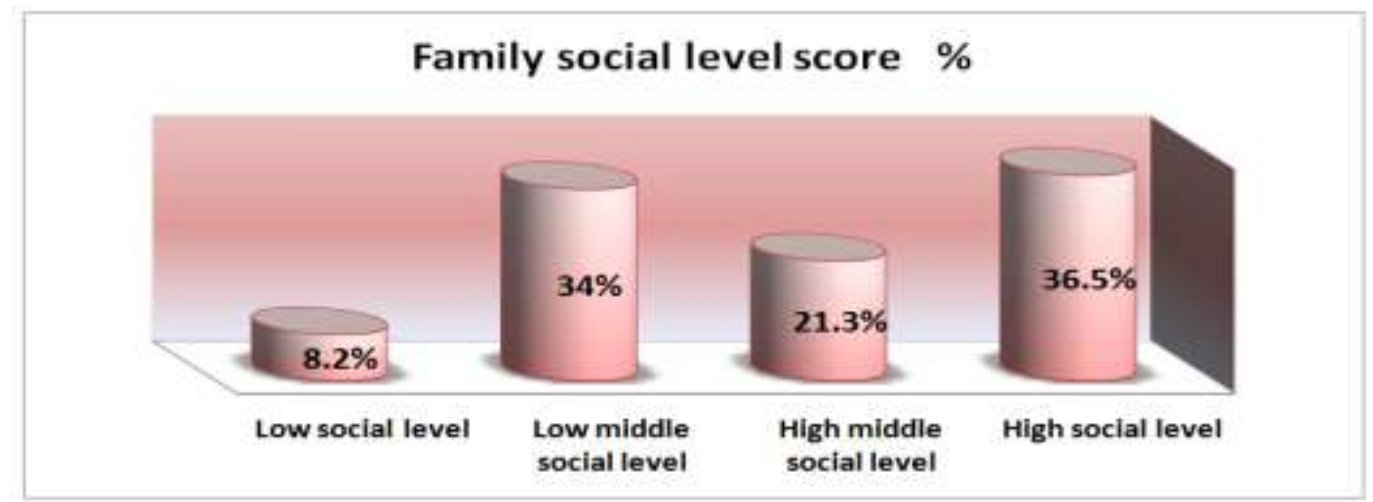

Figure (3): Distribution of the studied students regarding to their family score of social level

Figure (4): represents the studied school students to average hours they spend on the Internet per week. It illustrates that slightly more than half $(51.2 \%)$ of the participants were spent 1-6 hours on the Internet per week while, only slightly more than one - fifth (21.7\%) spend 13-19 hours on the Internet per week.

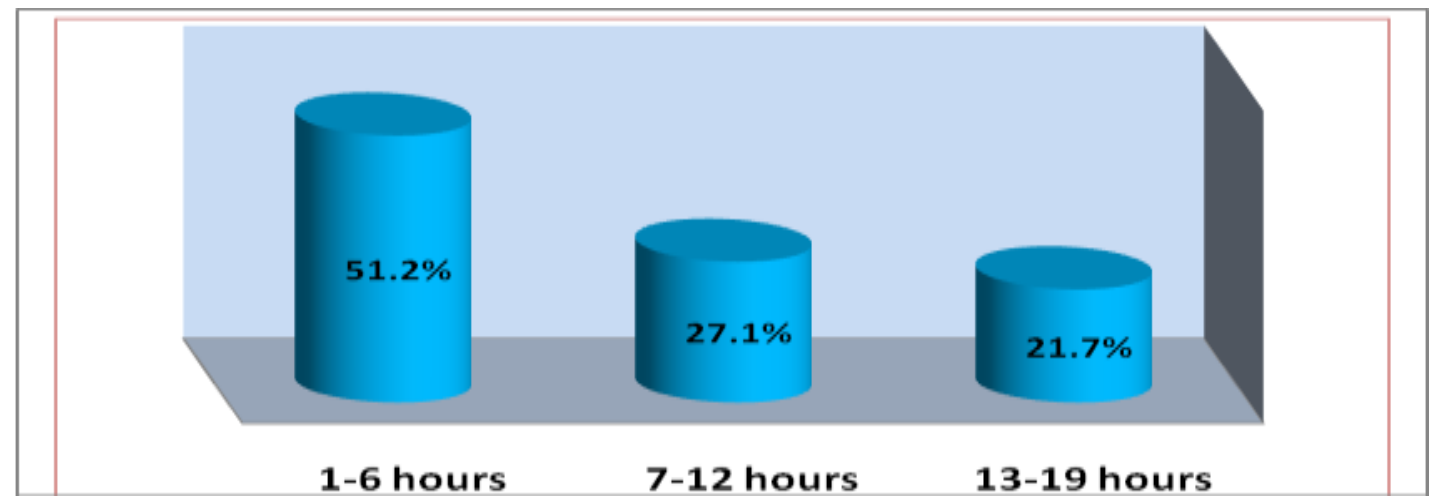

Figure (4): Distribution of the studied students according to average hours they spend on internet per week. 
Figure (5): It reveals that more than two- thirds $(67 \%)$ of the studied subjects use the Internet since three years or more while, one - third (33\%) of them were used the Internet since less or equal to one year.

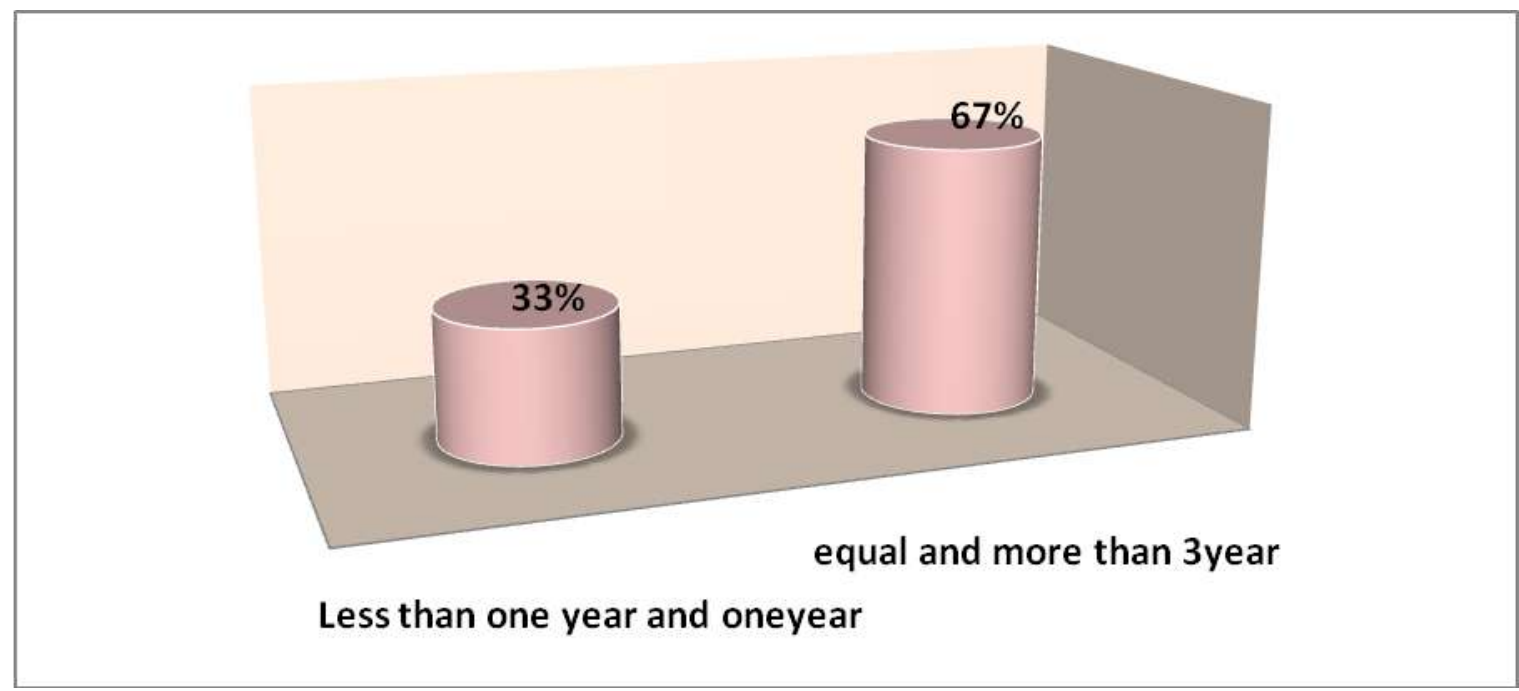

Figure (5): Distribution of the studied subjects according to years of using the Internet.

Figure (6): represent the studied students according to the number of using the Internet during academic and summer holiday days. It represents that slightly more than two- fifths $(42.7 \%)$ of the studied subjects use the Internet once per day and only $9.3 \%$ of them use Internet four- times or more during academic day while slightly more than half $(56.9 \%)$ of them use the internet four -times or more during summer holiday days and only $2.7 \%$ does not use the Internet.

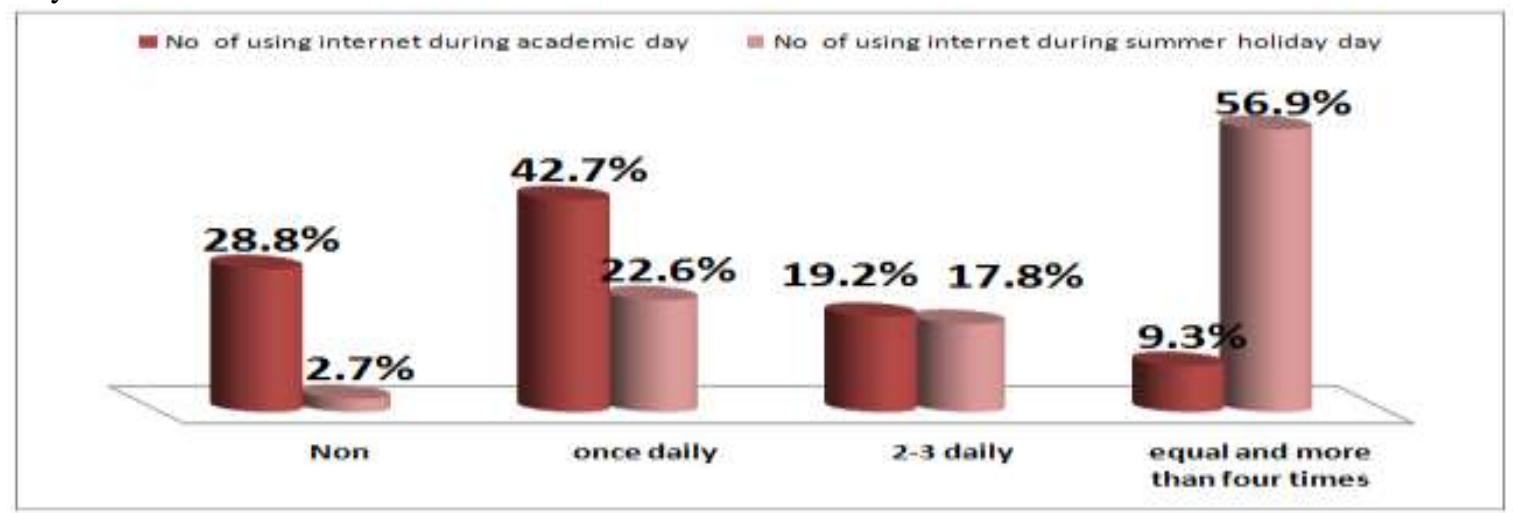

Figure (6): Distribution of the studied students according to number of using the internet during academic and summer holiday days.

Figure (7): represent the studied students according to places that they can use the Internet more in it. It shows that the majority $(93.5 \%$ and $91.2 \%)$ of the studied students reported Cyber and their friends or relatives while $1.4 \%$ of them reported home.

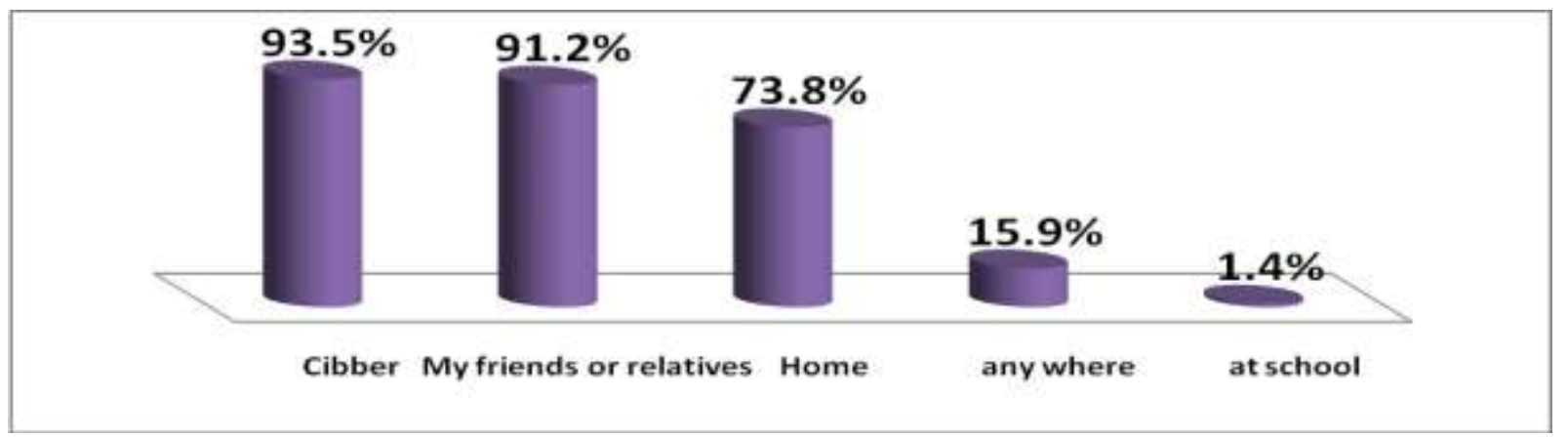

Figure (7): Distribution of the studied students according to places that they can use the internet more in it. (More than one answer allows). 
Figure (8): represent the studied students according to methods of the Internet use. It shows that the most ( 89.8\%) of the studied students reported Cibber followed by nearly two- thirds ( $61.5 \%$ and $60.7 \%$ ) reported mobile and original computer while $7.2 \%$ of them reported tablet or iPad.

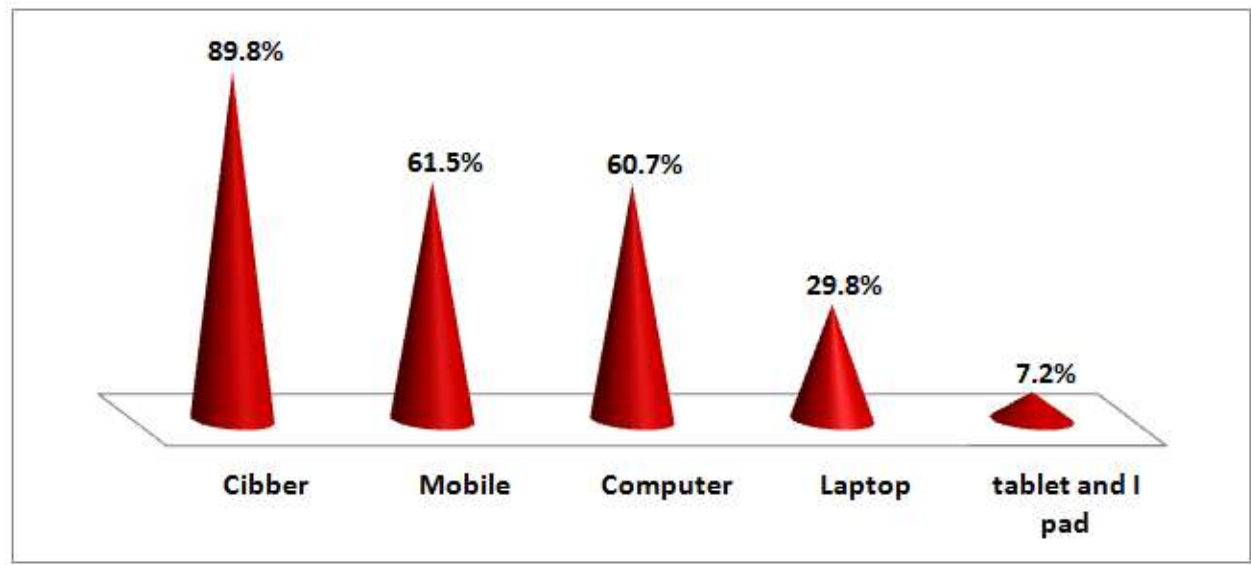

Figure (8): Distribution of the studied students according to methods of the internet use. (More than one answer allows).

Figure (9): represent the studied students according to their reported incentives for use the Internet. It shows that two- thirds ( 66\%) of the studied students reported for entertainment followed by $24.2 \%$ and $20.9 \%$ reported for search about knowledge and do social contact while $4.6 \%$ of them reported for sex excitement.

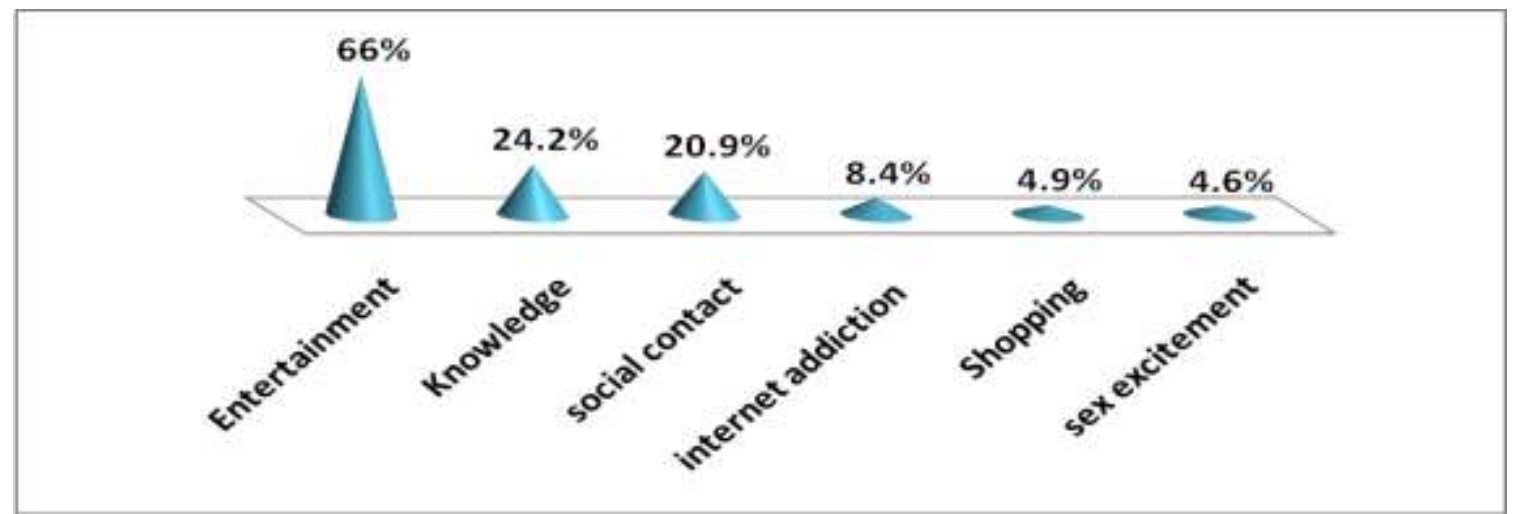

Figure (9): Distribution of the studied students according to their reported incentives for use the internet. (More than one answer allows).

Figure (10): represent the studied students according to their preferable site they use. It shows that three- fifths ( $61.4 \%)$ of the studied students reported Internet games followed by one- half and two fifth $(51.1 \%$ and $43.3 \%$ ) reported chatting room and scientific setting while $4.3 \%$ of them reported for sex setting.

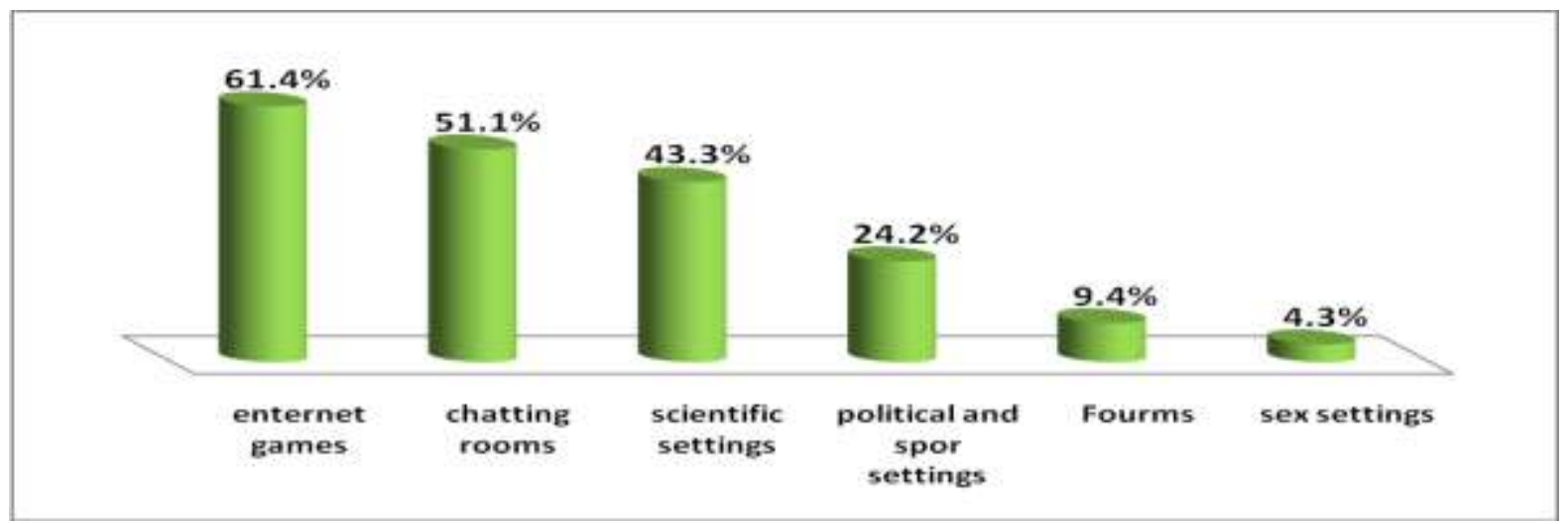

Figure (10): Distribution of the studied students according to their preferable site they use. (More than one answer allows). 
Figure (11): represent the studied students according to their reported causes for Internet addiction. It shows that slightly less than three quarters $(71.2 \%)$ of the studied students reported boring and empathy followed by slightly more than one - third reported loneliness (35.6\%) while $4.2 \%$ of them reported for privacy.

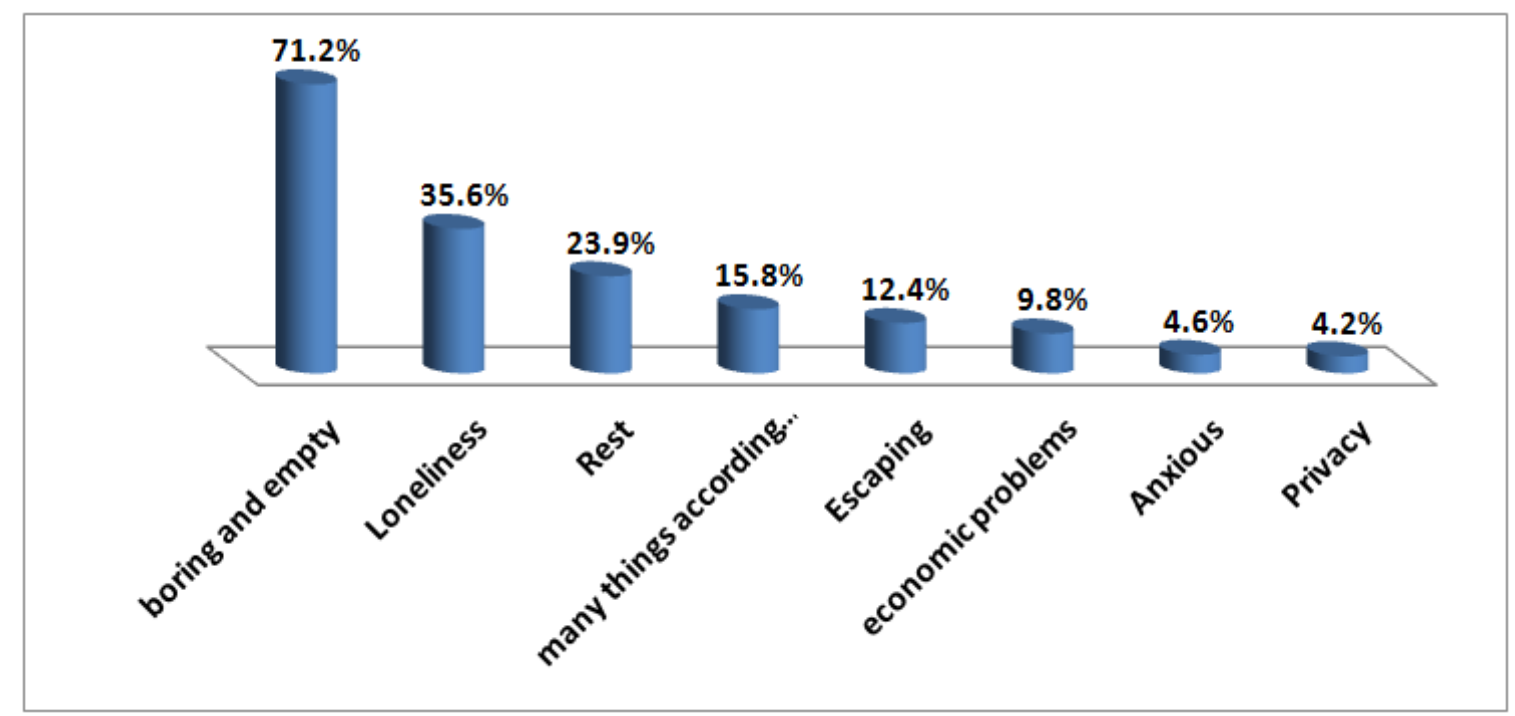

Figure (11): Distribution of representing the studied students according to their reported causes for internet addiction. (More than one answer allows).

Figure (12): represent the studied students according to their total score of Internet addiction scale. It shows that slightly less than two fifths $(37.8 \%$ ) of the studied students were Internet addicted students and slightly more than one- third $(36.7 \%)$ were excessive Internet users students while one- quarter( $25.5 \%)$ of them were normal Internet use students.

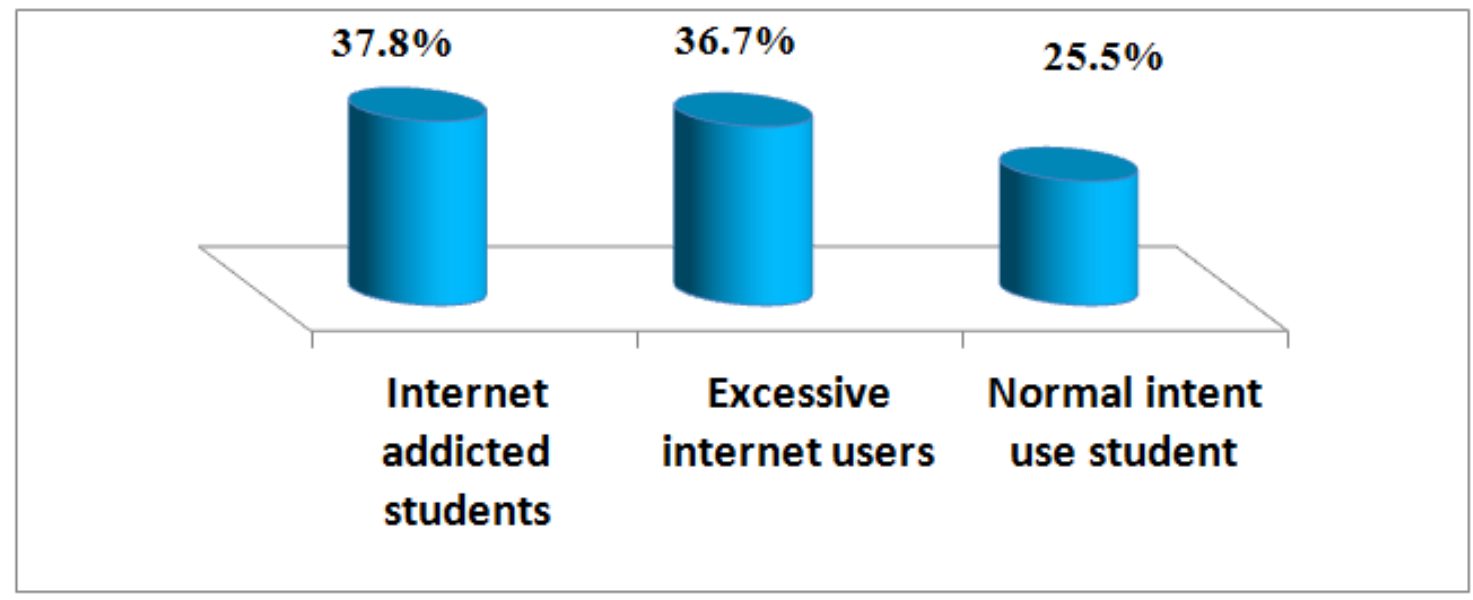

Figure (12): the studiedstudentsaccording to their total score of internet addiction scale.

Table (2) shows correlation between eight domains of internet addiction scale and total score internet addiction scale. The table revealed that, there was a significant positive correlation between all domains of internet addiction scale and total score internet addiction scale $\mathrm{p}=<\mathbf{0 . 0 0 1}$ respectively.

Table (2): correlation between eight domains of internet addiction scale and total score internet addiction scale.

\begin{tabular}{|c|c|c|c|c|c|c|c|c|c|}
\hline \multirow[t]{2}{*}{ Variables } & $\begin{array}{c}\text { score of } \\
\text { Salienc } \\
\mathrm{e}\end{array}$ & $\begin{array}{l}\text { score of } \\
\text { Mood } \\
\text { Modificati } \\
\text { on }\end{array}$ & $\begin{array}{c}\text { score of } \\
\text { Toleranc } \\
\mathrm{e}\end{array}$ & $\begin{array}{c}\text { score of } \\
\text { Withdraw } \\
\text { al } \\
\text { Symptoms }\end{array}$ & $\begin{array}{l}\text { score of } \\
\text { Conflict }\end{array}$ & $\begin{array}{l}\text { score of } \\
\text { Relapse }\end{array}$ & $\begin{array}{c}\text { score of } \\
\text { Dependen } \\
\text { ce }\end{array}$ & $\begin{array}{c}\text { score of } \\
\text { abuse }\end{array}$ & $\begin{array}{l}\text { Total } \\
\text { score }\end{array}$ \\
\hline & $\begin{array}{l}\mathbf{r} \\
\mathbf{p}\end{array}$ & $\begin{array}{l}\mathbf{R} \\
\mathbf{p}\end{array}$ & $\begin{array}{l}\mathbf{r} \\
\mathbf{p}\end{array}$ & $\begin{array}{l}\mathbf{R} \\
\mathbf{p}\end{array}$ & $\begin{array}{l}\mathbf{r} \\
\mathbf{p}\end{array}$ & $\begin{array}{l}\mathbf{R} \\
\mathbf{p}\end{array}$ & $\begin{array}{l}\mathbf{r} \\
\mathbf{p}\end{array}$ & $\begin{array}{l}\mathbf{r} \\
\mathbf{p}\end{array}$ & $\begin{array}{l}\mathbf{R} \\
\mathbf{P}\end{array}$ \\
\hline
\end{tabular}




\begin{tabular}{|c|c|c|c|c|c|c|c|c|c|}
\hline $\begin{array}{l}\text { score of } \\
\text { Salience }\end{array}$ & - & 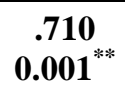 & ${ }^{.698}$ & $\begin{array}{l}.675 \\
0.001\end{array}$ & $\mathrm{.j33}^{\text {*.* }}$ & 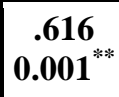 & $\begin{array}{l}.632 \\
0.001\end{array}$ & $\begin{array}{l}.435 \\
0.001\end{array}$ & ${ }^{.801}$ \\
\hline $\begin{array}{l}\text { score of Mood } \\
\text { Modification }\end{array}$ & .710 (0.001* & - & $\begin{array}{l}.692 \\
0.001 *\end{array}$ & $\begin{array}{l}.654 \\
0.001\end{array}$ & $\begin{array}{l}.351 \\
0.001\end{array}$ & $\begin{array}{l}.578 \\
0.001\end{array}$ & $\begin{array}{l}.606 \\
0.001\end{array}$ & $\begin{array}{l}.434 \\
0.001\end{array}$ & $\begin{array}{l}.775 \\
0.001 *\end{array}$ \\
\hline $\begin{array}{l}\text { score of } \\
\text { Tolerance }\end{array}$ & .698 & ${ }_{0.001}^{.692}$ & - & $\begin{array}{l}.769 \\
0.001^{* *}\end{array}$ & $\stackrel{.447}{0.001}{ }^{* *}$ & $\begin{array}{l}.677 \\
0.001^{* *}\end{array}$ & $\begin{array}{l}.686 \\
0.001\end{array}$ & .586 & $\begin{array}{l}.870 \\
0.001\end{array}$ \\
\hline \begin{tabular}{|l} 
score of \\
Withdrawal \\
Symptoms
\end{tabular} & ${ }^{.675}$ & ${ }^{.654}{ }^{* *}$ & $\begin{array}{c}.769 \\
0.001^{* *}\end{array}$ & - & $\stackrel{.436}{0.001}{ }^{* *}$ & $\begin{array}{l}.755 \\
0.001\end{array}$ & $\begin{array}{l}.712 \\
0.001\end{array}$ & ${ }^{.591}{ }^{* 001}{ }^{* *}$ & $\begin{array}{l}.885 \\
0.001^{* *}\end{array}$ \\
\hline score of Conflict & $\begin{array}{l}.333 \\
0.001\end{array}$ & $\begin{array}{l}.351 \\
0.001\end{array}$ & $\begin{array}{l}.447 \\
0.001\end{array}$ & $\begin{array}{l}.436 \\
0.001\end{array}$ & - & $\begin{array}{l}.444 \\
0.001\end{array}$ & $\begin{array}{l}.467 \\
0.001\end{array}$ & $\begin{array}{l}.354 \\
0.001^{* *}\end{array}$ & $\begin{array}{l}.515 \\
0.001\end{array}$ \\
\hline score of Relapse & ${ }^{.616}{ }^{\text {*001 }}$ & $\begin{array}{c}.578 \\
0.001\end{array}$ & ${ }_{0.001}^{.677}$ & $\begin{array}{l}.755 \\
0.001\end{array}$ & $\begin{array}{l}. .444 \\
0.001\end{array}$ & - & $\begin{array}{l}.735 \\
0.001\end{array}$ & $\begin{array}{l}.576 \\
0.001\end{array}$ & $\begin{array}{r}.839 \\
0.001 * *\end{array}$ \\
\hline $\begin{array}{l}\text { score of } \\
\text { Dependence }\end{array}$ & $\begin{array}{l}.632 \\
0.001 * *\end{array}$ & $\begin{array}{l}.606 \\
0.001\end{array}$ & ${ }^{.686}$ & $\begin{array}{l}.712 \\
0.001 * *\end{array}$ & $\begin{array}{l}.467 \\
0.001^{* *}\end{array}$ & $\begin{array}{l}.735 \\
0.001\end{array}$ & - & .611 & $\begin{array}{r}.853 \\
0.001 * *\end{array}$ \\
\hline score of abuse & $\begin{array}{l}.435 \\
0.001^{* *}\end{array}$ & $\stackrel{.434}{0.001}{ }^{* *}$ & ${ }^{.586}$ & $\begin{array}{l}.591 \\
0.001\end{array}$ & $\mathbf{0 . 0 0 1}^{.354}$ & $\begin{array}{l}.576 \\
0.001\end{array}$ & ${ }^{.611}$ & - & $\begin{array}{l}.726 \\
0.001 * *\end{array}$ \\
\hline Total score & $\begin{array}{l}.801 \\
0.001\end{array}$ & $\begin{array}{l}.775 \\
0.001\end{array}$ & $\begin{array}{l}.870 \\
0.001 * *\end{array}$ & $\begin{array}{l}.885 \\
0.001 * *\end{array}$ & $\begin{array}{l}.515 \\
0.0011^{* * *}\end{array}$ & $\begin{array}{r}.839 \\
0.001 *\end{array}$ & $\begin{array}{l}.853 \\
0.001\end{array}$ & $\begin{array}{l}.726 \\
0.001^{* *}\end{array}$ & - \\
\hline
\end{tabular}

\section{Discussion}

In the last decade, an explosive growth in the use of Internet not only in Egypt but also worldwide and growing concerns for what has been labeled as Internet addiction worldwide. Dr. Ivan Goldberg in 1995 was proposed the term "Internet addiction" for pathological compulsive Internet use. Internet addiction adversely affects lives by causing physical, psychological and social problems. Forty- five present of world Internet users is young adults. In developing countries, $30 \%$ of the below twenty - five years age group are Internet users ${ }^{(21}$, ${ }^{22)}$. Hence, it is necessary to study incentives of Internet use and its addiction among adolescents especially in rural areas.

The findings of the present study revealed that the adolescents' age ranged from 12-18 years old. These findings were in accordance with Çiçekoğlu etal., 2013 who reported that the average age of adolescents included into the study was $13.06 \pm 0.96$ years old ${ }^{(23)}$ and Kimetal., 2010 found that their study participants were between the ages of 13 and 15 years with a mean age of 14 years $^{(7)}$. While, Sharma et al., 2014 reported that the mean age of the study subjects was $19.02( \pm 1.450)$ years old $^{(17)}$.

All over the world, the Internet is developing into a main portion of everyday life and its use increases especially among young people. Internet addiction is a broad concept. Internet addiction is a very serious problem for adolescents. One of the modernist communication tools is the Internet, which essentially can alteration and does easier the ways of connection between humaneness, it removes geographical partitions and reduces genuine distances. More time lay out in misery seclusion and less time spends with authentic people in their lives by people who are suffering from the Internet addiction and are often saw as socially wooden ${ }^{(22)}$.

As regards average of hours spend on Internet per -week, years of using the Internet, several times of using the Internet during academic day and during the summer holiday. The findings of the present study revealed that more than half of the study subjects spent 1-6 hours on the Internet per week, more than twothirds of them equal and more than three years ago of using the Internet and nearly half of them used the Internet once daily during academic day but more than half of the study subjects used Internet two to three times daily during the summer holiday. These results in disagreement with Çiçekoğlu et al.,2013 study carried out with six to eight grade students, it was identified that two- thirds of their studied subjects were applied the Internet for less than one hour per day and at least three times per week ${ }^{(23)}$. 
On the other hand, these findings were similarly with Hawi 2012 who found that the intermediate number of hours of Internet application per day after schoolwas6.2 hours; on holidays, itwas10.6hoursandYeap et al., 2015 who found that nearly two- thirds of the studied subjects spent more than three hours in using the Internet $(24,25)$.While, Sharma et al., 2014 reported that average time spent on the Internet was $(1.29 \pm 1.251)$ hours per day, with more than sixty percent of studied subjects $(65.7 \%)$ spending less than 2 hours per day on Internet. Also, Grover et al.,2010 in their study found the mean time spent in the Internet use was $2.13 \mathrm{~h}$ (SD 1.98) everyday, more than half $(56.73 \%)$ of the sample was applying Internet at least $2 \mathrm{~h} / \mathrm{day}^{(17,26)}$.

A different types of the Internet activities like as online gaming, gambling, social sites, permissive utilization, and media, etc can lead to Internet addiction ${ }^{(27)}$. In relation to places, methods, incentives, causes and most preferred sites that can study subjects used Internet. The results of the current study revealed that the plurality of the studied subjects reported cyber, friends and relatives and home as the most places of Internet used; computer and mobile most common methods; nearly two- thirds of them reported that their incentives for using the Internet were entertainment followed by gain knowledge and social contact; internet games, chatting rooms followed by scientific settings were the most preferred sites of Internet; about causes of the Internet addiction more than two- thirds of them reported boring and empty, followed by loneliness and rest .These results differ with the findings of the study conducted by Marahatta et al., 2015 who reported that the Internet was being used for several aims such as examination emails and messages (76.7\%), online shopping (15.67\%), readability news $(61.01 \%)$, Blogging $(6.35 \%)$, scientific searches $(58.9 \%)$ but these results look alike with its results in $32.6 \%$ of their studied subjects played online games on Internet ${ }^{(27)}$.

Several studies were conducted in India, Lebanon and Taiwan reported that played online games the most incentives for using Internet ${ }^{(24,29,30)}$ Salehi et al., 2014 found that the studied subjects of their study identified the essential aims of using Internet according to their order of its importance are examination emails, scientific search, connecting with friends and families, downloading films and music, chatting with new people, Internet shopping, blogging, and finally playing games. In this study, chatting with new people, connecting with friends and families and online gaming are the most frequent use of Internet among problematic Internet users ${ }^{(31)}$. Hawi 2012 who found that internet activities ranked as follows: communication and messaging $(84.2 \%)$, information and research $(65.7 \%)$,entertainment such as gaming $(51.8 \%)$, music and movies $(51.2 \%)$ and others $(4.8 \%)^{(24)}$. Çiçekoğluetal.,2013 found that $71.2 \%$ of the studied subjects applied the Internet for education, homework, gaining information, recreation, playing and chatting ${ }^{(23)}$.

The rising publicity of the Internet among adolescents has turn into a significant social context for their evolution either in a positive way or negative way. The higher use of the Internet would raise the danger of being alone and decrease interaction and interpersonal connection and, the greatest had no proper guidance and monitoring, which would increase the risk taking the behavior of the adolescents. The Internet should be used in the right course with appropriate direction from the caretakers ${ }^{(32)}$.Exaggerated use of Internet is one of the main problems in today's society. Therefore, various studies have been carried out in different age groups to determine the spread of Internet addiction ${ }^{(6)}$.In the present study, internet addiction was deliberate by using $\mathrm{Al}$ Osaymi2010's Internet addiction scale. The researchers reported that more than one- third of the studied subjects $37.80 \%$ were Internet addiction and one- quarter of them normal users of Internet and the mean score obtained by the studied subjects on Internet addiction scale was132.73 \pm 29.848 . The findings of this study were in accordance with Al-Osaymi 2010 who found that $26.57 \%$ of studied subjects were Internet addiction and $24.87 \%$ of them were non-Internet addiction ${ }^{(19)}$. Çiçekoğlu etal., 2013 found that the mean score gained by the studied subjects on the Internet Addiction Scale (IAS) was $75.71 \pm 27.68^{(23) \text {. }}$

Sharmaet al., 2014 used Young's Internet addiction scale for measuring Internet addiction in their study, they reported that more than half $(57.3 \%)$ students were normal users while more than one third of them $(35.0 \%)$ have mild Internet addiction, only $7.4 \%$ students have moderate addiction and the rest of them $0.3 \%$ have severe addiction to Internet, so, joining mild, moderate and severe addictions, a total of $42.7 \%$ students were addicted to internet ${ }^{(17)}$. A study on the prevalence of the internet addiction in Indian adolescents reported the prevalence at $0.7 \%^{(33)}$. Chathoth et al., 2013 reported that the prevalence of Internet addiction was $18.88 \%$ in undergraduate Medical students in Mangalore which was representing moderate and severe addiction ${ }^{(34)}$. While a study on internet addiction disorder among medical students in China reported a prevalence of $16.2 \%$ student ${ }^{(35)}$. Mashaei et al., 2013 found in their study had been done in students of Rafsanjan University of Medical Sciences, Iran, that the prevalence of Internet addiction was more than half of students ( $51.3 \%)$ mild, the lowest frequencies $5.4 \%$ moderate and $0.9 \%$ severe, while more than two- thirds $42.4 \%$ of students were not addicted to the Internet ${ }^{(36)}$.

Hashemianetal., 2014reported that more than half $(57.4 \%)$ of all studied subjects hadn't Internet addiction and more than one third of them $(43.6 \%)$ had mild and moderate Internet addiction ${ }^{(37)}$. Quite characteristically in a 2012 research conducted in Hong Cong, among 3328 students aged 12.59 \pm 0.74 , a 26,4\% was found addicted to the internet ${ }^{(38)}$. Different studies have reported a wide range of Internet addiction. In a review study, $3 \%-38 \%$ of all studied subjects had an Internet addiction ${ }^{(39)}$. In another study, $17.9 \%$ of 
Taiwanese students had Internet addiction ${ }^{(40)}$. In an Iranian study, the prevalence of Internet addiction was reported to be $10.8 \%$ in medical students ${ }^{(41)}$. Internet addiction in young individuals is especially famed as the asocial problem. Previous epidemiological studies using community self-report survey reported that the spread of IA in adolescents extended from $38 \%$ to $90 \%{ }^{(33,42)}$. Reasons for a vast diversity in the prevalence rates may be concerning to various research layouts, different assessment measurements, or several diagnostic standard, different of residence areas, differences in public and educational backgrounds, and difficulty in conceptualizing Internet addiction, heterogeneity of population studied, lack of availability of standard diagnostic criteria, studies failing to distinguish between main and pointless Internet use, and non-respect of psychiatric comorbidity in some of the studies.

Fast technological developments, as well as increasingly easier access to the Internet, is one of the agents affecting the number of persons addicted to the Internet ${ }^{(43) .}$ The results of these study revealed that there was a positive correlation between total score of the scale of Internet addiction and an average of hours spend weekly on the Internet, years of using the Internet, a number of times spend on the internet during school times and holyday, academic year and social class except sex $(\mathrm{p}=0.000)$. Several studies were disagreement with these findings of the study which found that there was a significant relation between gender and Internet addiction ${ }^{(18,}$ 31, 41). While, Sharmaet al., 2014 found that a significant relation between hours spent using Internet and existence of Internet addiction $(\chi 2=43.940, p=0.000)^{(17)}$.

Internet perversion is more among the rural adolescents, and this calls for appropriate education and sensibility programs to the adolescents particularly in rural areas ${ }^{(4)}$.

\section{Conclusion}

Internet addiction is considered as a significant issue in adolescents and young adults. The present study illustrated that the plurality of the study subjects reported cyber, friends and relatives and home as the most places of Internet used; computer and mobile most common methods; nearly two- thirds of them reported that their incentives for using Internet were entertainment followed by gain knowledge and social contact; Internet games, chatting rooms followed by scientific settings were the most preferred sites of Internet; regarding causes of Internet addiction more than two- thirds of them reported boring and empty ,followed by loneliness and rest. Finally, about $37.8 \%$ of the students were Internet addicted, $36.7 \%$ were excessive Internet users and $25.5 \%$ were normal Internet use.

Based on the results of the present study:-

\section{Recommendations}

1. Establishing internet education unit in every school to educate students about safe use of internet to prevent the addiction.

2. Involve parents and teachers in caring \&observing their children and students during using internet.

3. Perform different workshops for students about physical, psychological and social risks of excessive internet use.

4. Many researches are needed in these areas to help parents, teachers, and policy makers to maximize the positive effects and minimize the negative effects of the Internet on elementary and secondary school students' lives.

References
[1]. The second decade: improving adolescent health and development. World Health Organization, Geneva: WHO, 2001: 1-20.

[2]. INCLEN international clinical epidemiology network. 1998-2001. Available from: www.inclen.org. (accessed on 20th Dec 2010)

[3]. Improving adolescent health and development. The second decade WHO/FRH/ADH/98.18;p.2.

[4]. Koovakkai D and Muhammed P S. Internet abuse among the adolescents: a study on the locale factor.Webology, 2010;7(1).http://www.webology.org/2010/v7n1/a75.html

[5]. Sargin N. Internet attitudes and problematic internet use of university students. Turkish Journal of Education, 2013;2 (2): 44-53.

[6]. Kormas G, Critselis E, Janikian M, Kafetzis2 D and Tsitsika A. Risk factors and psychosocial characteristics of potential problematic and problematic internet use among adolescents: A crosssectional study.BMC Public Health, 2011; 11:595-562. http://www.biomedcentral.com/14712458/11/595

[7]. Kim1Y, Park JY, Kim S B, Jung I, Lim YS and Kim J. The effects of Internet addiction on the lifestyle and dietary behavior of Korean adolescents. Nutrition Research and Practice (Nutr Res Pract) ,2010;4(1):51-57 .DOI: 10.4162/nrp.2010.4.1.51

[8]. Internet users in the world: distribution by world regions - 2012, Q2. Internet World Stats: Usage and population statistics. Available from: URL: http://www.internetworldstats.com/stats.htm. 
[9]. Tsitsika A, Janikian M, Schoenmakers TM, Tzavela EC, Olafsson K, WojcikS,Makaruk K, Critselis E, Müller KW, Dreier M, Holtz S, Wölfling K, Iordache A, Oliaga A, Chele G, Macarie G and Richardson C. Internet addictive behavior in adolescence: a cross-sectional study in seven European countries. CyberpsycholBehavSocNetw, 2014; 17(8):528-35.

[10]. China Internet Network Information Center. The Statistical Report of the Development of China Internet Network, No.31. www.cnnic.net.cn/hlwfzyj/hlwxzbg/hlwtjbg/201301/t20130115_38508.htm (accessed Jan. 15, 2013).

[11]. Rideout VJ, FoehrUG and Roberts DF. Generation M2. (2010) Media in the lives of 8- to 18-year olds. A Kaiser Family Foundation Study. www.kff.org/entmedia/upload/8010 .pdf (accessed Mar. 8, 2011).

[12]. Şahin C. An analysis of internet addiction levels of individuals according to various variables. TOJET: The Turkish Online Journal of Educational Technology, 2011; 10(4): 60-66.

[13]. Arisoy Ö. Internet addiction and its treatment. Current Approaches in Psychiatry, 2009; 1(1): 55-67.

[14]. Ko CH, Yen JY, Liu SC, Huang CF and Yen CF. The associations between aggressive behaviors and Internet addiction and online activities in adolescents. J Adolesc Health 2009; 44:598-605.

[15]. Seo M, Kang HS, Yom YH. Internet addiction and interpersonal problems in Korean adolescents. Comput Inform Nurs, 2009;27: 226-33.

[16]. Çelen FK, Çelik A and Seferoğlu S. Children's internet usage and online risks they face. Academic Computing Conference, Malatya, Turkey, 2-4 February 2011.

[17]. Sharma A, SahuR, KasarPK and Sharma R. Internet addiction among professional courses students: A study from central India. International Journal of Medical Science and Public Health , 2014 ; 3 (9):10691073 .

[18]. Waugn R. Internet addiction can cause physical damage to the brain, just like drugs, say researchers.2012. Retrieved on Feb. 20, 2014, from http://www.dailymail.co.uk/sciencetech/article2085369/Internet-addiction-cause-physical-damage-brain-just-like-drugs-say-researchers.html.

[19]. Al-Osaymi SAM. Internet addiction and Its Relationship to Psychosocial-Social Adjustment among the Secondary School Students in Riyadh. Thesis .M.sc., College of Graduate Studies, Naîf Arab University for Security Sciences, 2010.

[20]. Fahmy and El-Shrbini . Modified social score for family social leveling. The Bulletin of the High Institute of Public Health. Vol XIII No-5-2008.

[21]. Grover S, Chakraborty K, and Basu D. Pattern of Internet use among professionals in India. Indian J Psychiatry. 2010; 19(2): 94-100.

[22]. Ghosh SM .Internet addiction among school going adolescents. International Journal of Multidisciplinary Research and Development, 2015; 2(3): 453-456

[23]. Çiçekoğlu P, Durualp E and Durualp E. Evaluation of the level of internet addiction among 6th-8th grade adolescents in terms of various variables. European Journal of Research on Education, Special Issue: Educational Technology and Lifelong Learning,2014: 22-28.

[24]. Hawi NS. Internet addiction among adolescents in Lebanon. Computers in Human Behavior,2012; 28: 1044-1053.

[25]. Yeap JA, Ramayah T, Kurnia S, Abdul Halim H and Ahmad NH. The assessment of internet addiction among university students : some findings from a focus group study.Tehničkivjesnik, 2015; 22( 1$)$ : 105111

[26]. Grover S, Chakraborty K and Basu D. A survey of Internet use pattern among professionals. Ind Psychiatry J, 2010;19:94-100.

[27]. Mishra S, Draus P, GorevaN ,Leone G and Caputo D. the impact of internet addiction on university students and its effect on subsequent academic success: A survey study issues in information systems , 2014; 15(1): 344-352.

[28]. Marahatta SB, Adhikari B, Aryal N and Regmi R . Internet Addiction and Associated Factors among Health Sciences Students in Nepal. J Community Med Health Educ, 2015; 5: 362. doi:10.4172/21610711.1000362.

[29]. Chathoth V, Kodavanji B, Arunkumar N and Pai SR. Internet behavior pattern in undergraduate medical students in Mangalore. International Journal of Innovative Research in Science, Engineering and Technology,2013; 2: 2133-2136.

[30]. Faraci P, Craparo G, Messina R and Severino S. Internet Addiction Test (IAT): Which is the best factorial solution? Journal of Medical Internet Research, 2013; 15: 10.

[31]. Salehi M, NoroziKhalili M, Hojjat S, Salehi M and Danesh A. Prevalence of Internet Addiction and Associated Factors Among Medical Students From Mashhad, Iran in 2013.Iran Red Crescent Med J, 2014; 16(5). DOI: 10.5812/ircmj.17256.

[32]. Govindappa L, Kasi S and Henry G. Internet use and risk taking behaviours among adolescents. The Indian J Pediatr. 2013 10.1007/s 12098-013-1093-9. 
[33]. Goel D, Subramanyam A and Kamath R. A study on the prevalence of internet addiction and its association with psychopathology in Indian adolescents. Indian J Psychiatry 2013;55:1403.doi:10.4103/00195545.111451PMID:23825847

[34]. Chathoth VM, Kodavanji B, Nayanatara AKand Pai SR. Internet behaviour pattern in undergraduate medical students in Mangalore. International Journal of Innovative Research in Science, Engineering and Technology 2013;2.

[35]. Liu X, Bao Zand Wang Z. Internet Use and Internet Addiction Disorder Among Medical Students: A Case from China. Asian Social Science 2010;6:1.

[36]. Mashaei N, Mohammad A, Ahmad PB, Omid R, Ayatollahi A, reza B, et al. The Prevalence of Internet Addiction amongthe Students OfRafsanjani University Of Medical Sciences. ASEAN Journal of Psychiatry 2013; 14:109-16.

[37]. Hashemian A, Direkvand-MoghadamA, Delpisheh A and Direkand-Moghadam A.Prevalence of Internet Addiction among University Students in Ilam: a Cross-sectional Study. International Journal of Epidemiologic Research, 2014; 1 (1): 9-15.

[38]. Shek, Daniel T.L. / Yu, Lu. Internet addiction in Hong Kong adolescents: profiles and psychosocial correlates,International Journal on Disability and Human Development, Published Online: 27/02/2012 ISSN (Online) 2191-036.

[39]. Chakraborty K, Basu Dand Vijaya Kumar KG. Internet addiction: consensus, controversies, and the way ahead. East Asian Arch Psychiatry. 2010; 20(3): 123-32.

[40]. Tsai HF, Cheng SH, Yeh TL, Shih CC, Chen KC, Yang YC, et al. The risk factors of Internet addiction-a survey of university freshmen. Psychiatry Res. 2009; 167(3): 294-9.

[41]. Ghamari F, Mohammadbeigi A, Mohammadsalehi N and Hashiani AA. Internet addiction and modeling its risk factors in medical students, Iran. Indian J Psychol Med. 2011; 33(2): 158-62.

[42]. KardefeltWinther D. A conceptual and methodological crique of internet addiction research: toward a model of compensatory internet use. Comput Human Behav.2014;31:351-4.

[43]. Pawłowska B, Zygo M, Potembska E, Kapka-Skrzypczak L, Dreher P and Kędzierski Z. Prevalence of Internet addiction and risk of developing addiction as exemplified by a group of Polish adolescents from urban and rural areas. Ann Agric Environ Med, 2015; 22(1): 129-136. doi: 10.5604/12321966.1141382 